\title{
Dichotomophthora sp. causing leaf spot and foliar abscission on Anredera cordifolia in Brazil
}

\author{
Dartanha J. Soares ${ }^{1} \cdot$ Katia L. Nechet $^{2}$
}

Received: 12 June 2017 / Accepted: 7 September 2017 / Published online: 15 September 2017

(C) Australasian Plant Pathology Society Inc. 2017

\begin{abstract}
Dichotomophthora sp. is described as causing leaf spot and early foliar abscission on Anredera cordifolia in Brazil. Morphologically, the fungus fits with D. lutea, however, ITS sequence showed high homology with Bipolaris sp. recorded on Basella alba in Florida and with D. portulacae recorded on B. rubra in China. Additional studies are needed to clarify the taxonomic status of Dichotomophthora species on members of Basellaceae.
\end{abstract}

Keywords Basellaceae · Dematiaceous hyphomycete · ITS · Tropical fungi

Anredera cordifolia (Basellaceae), also known as madeira or mignonette vine, is a highly invasive species in Australia and in some Pacific Islands (CABI 2015). This species is native to South America, including Brazil, and was introduced into several countries as an ornamental plant (Heywood et al. 2007). In January 2016, several plants of A. cordifolia showing a foliar spot were observed in Jaguariúna, São Paulo (Southeast Brazil). The symptoms were initially characterized by small circular brown dots, with reddish margins, sometimes becoming confluent, later evolving to large blighted areas, sometimes with concentric rings and profuse fungal sporulation, resulting in early foliar abscission (Fig. 1).

Samples were collected and examined under a stereomicroscope. A dematiaceous hyphomycete was consistently found

Dartanha J. Soares

dartanha.soares@embrapa.br

1 Embrapa Algodão, Rua Oswaldo Cruz, 1143, Centenário, Campina Grande, PB 58428-095, Brazil

2 Embrapa Meio Ambiente, Rod. SP-340, Km 127,5, Tanquinho Velho, Jaguariuna, SP 13820-000, Brazil associated with the observed symptoms. Using a sterile needle, the fungal structures present on the surface of the foliar spots were aseptically transferred to potato-dextrose-agar (PDA), which were then incubated at $25^{\circ} \mathrm{C}$ for two days. The resulting colonies were aseptically transferred to PDA to obtain pure cultures. The two isolates obtained were deposited in the culture collection of the Embrapa Meio Ambiente (Coleção de Culturas de Microrganismos de Importância Agrícola e Ambiental) as accession numbers CMAA 1612 and CMAA1613.

Fungal structures obtained directly from symptomatic leaves, and also from cultures, were examined under a Leica DM2500 microscope. Measurements of relevant fungal structures were taken with the Interactive Measurement of the LAS® software v. 4.1 package. DNA was extracted from the two isolates using the Ultraclean ${ }^{\circledR}$ Microbial DNA Isolation Kit (Quiagen, Carlsbad). Mycelium obtained from colonies growing on potato-dextrose broth were filtered and ground in a mortar and pestle using liquid nitrogen. The internal transcribed spacer rDNA region (ITS) was amplified using primers ITS1 and ITS4 (White et al. 1990). The amplified PCR products were purified according to the ethanol precipitation method of Green and Sambrook (2012) and sequenced using the Big Dye ${ }^{\circledR}$ Terminator v 3.1 Cycle Sequencing Kit. Sequencing was performed by Instituto de Biociências of Universidade de São Paulo using the ABI 3730 DNA Analyser. ITS sequence of isolates CMAA 1612 and CMAA 1613 were deposited in GenBank as accession numbers MF196163 and MF196162, respectively. Pathogenicity tests were performed depositing 7-day-old mycelial discs of isolate CMAA 1613, grown on PDA, on leaves of A. cordifolia (Basellaceae), Portulaca oleraceae and P. grandiflora (Portulacaceae) and Zigocactus truncatus (Cactaceae), which were then maintained in a dew chamber, at $25 \pm 2{ }^{\circ} \mathrm{C}$ and $\mathrm{RH}>90 \%$, for $72 \mathrm{~h}$. 
Fig. 1 Symptoms of Dichotomophthora sp. on Anredera cordifolia. a Initial symptoms; (b) Advanced symptoms leading to early senescence; (c) Earlier senesced leaves under high humid conditions; (d) close up of foliar spot showing the pathogen signals (conidiophore and conidia)
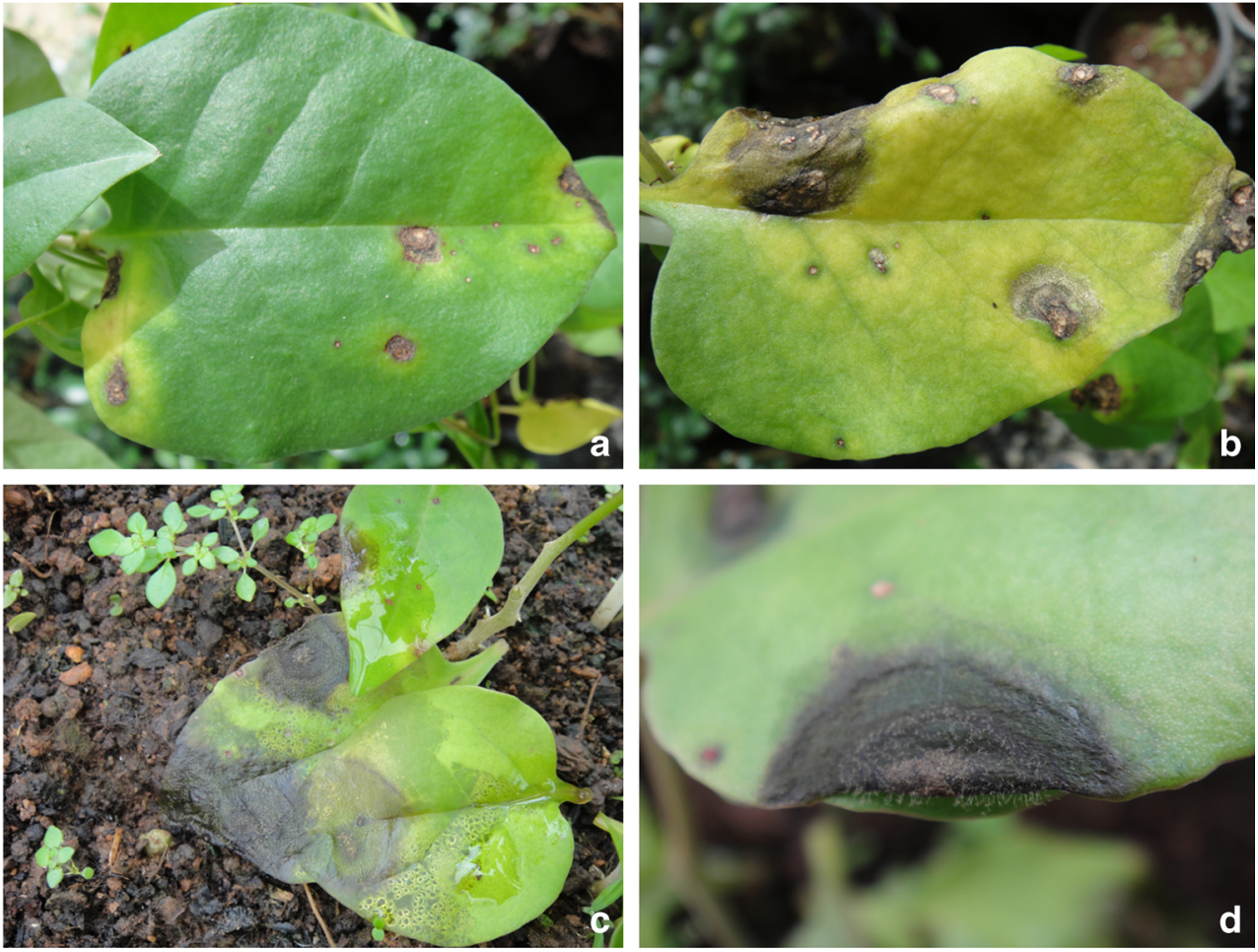

The conidiophores observed were pale brown to brown, erect, simple or irregularly branched, sometimes verruculose near the apex, up to $900 \mu \mathrm{m}$ long and 9-12 $\mu \mathrm{m}$ wide, "conidiogenous head" usually divided 3 to 4 times (Fig. 2a), frequently proliferating to produce additional heads (Fig. 2b); conidia were initially subhyaline, becoming brown to reddishbrown, solitary, smooth to finely verruculose (Fig. 2c-e), 1-6septate, ellipsoidal to cylindrical, sometimes slightly curved, 24-94 × 10-17 $\mu \mathrm{m}$, with rounded ends (Fig. 2c). Abundant immersed sclerotia were formed on PDA, and also on oatmeal agar, after 20 days at dark, while in malt-extract-agar only few, scattered sclerotia were observed. Based on the above characteristics, the fungus was identified as belonging to the genus Dichotomophthora. Using the ITS sequence on a megablast search in the NCBIs GenBank nucleotide database, the closest hits obtained were Bipolaris sp. SZ-2011 (GenBank JF506092; Identities = 521/526 (99\%), gaps $=2 / 526(0 \%))$ which was isolated from Basella alba in Florida (Zhang et al. 2011) and Dichotomophthora portulacae strain MXC 13071707 (GenBank KJ696544; Identities = 466/470 (99\%), no gaps) isolated from B. rubra in China (Jing et al. 2008).

Based on morphological characterization, the fungus herein described resembled $D$. lutea more than D. portulacae. Dichotomophthora lutea differs from $D$. portulacae mainly based on conidiophore length and terminal cells arrangement, and conidia width (de Hoog and van Oorschot 1983). However, later works have reported a great variability on conidiophores and conidia size of what they have called "D. portulacae", overlapping species circumscriptions (Eken 2003; Jing et al. 2008). A third species, D. cactacearum, known only from Brazil, can be easy distinguished based on morphological traits (Da Ponte and Freire 1972).

The Dichotomophthora sp., herein, was able to infect its original host (A. cordifolia) and also P. oleraceae and $P$. grandiflora. No symptoms were observed on $Z$. truncatus (Fig. 3). The fungus was reisolated from the symptomatic inoculated leaves and had the same morphology as described above, fulfilling Koch's postulates.

As mentioned, the present fungus is morphologically distinct from $D$. portulacae, although we demonstrated that it can infect Portulaca oleracea, the original host from where D. portulacae has been described. On the other hand, although our specimen is morphologically close to D. lutea, there is no sequence of the type strains of $D$. portulacae (CBS 174.35) and D. lutea (CBS 145.57) available to compare and confirm that they are indeed two separated species. Furthermore, later works report high variability on conidial and conidiophore sizes of $D$. portulacae, so we decided not to apply, at this moment, a specific epithet to the fungus causing leaf spot on A. cordifolia. However, considering that D. portulacae and D. lutea are indeed distinct species, based solely on morphological traits, we conclude that the fungus causing the symptoms observed on A. cordifolia is likely to be D. lutea.

Since their original descriptions, D. portulacae and D. lutea have been reported on several other hosts, including members of the Cactaceae (Farr and Rossman 2017). However, although the genus Dichotomophthora was previously reported on other members of Basellaceae, to our knowledge, this is the first report of this genus on Anredera worldwide. Additionally, due to the morphological and ITS 
Fig. 2 Dichotomophthora sp. isolated from Anredera cordifolia. a Conidiophores apices showing conidiogenous heads; (b) Proliferation of a conidiogenous head; (c) Conidia; (d) Conidium superficial view; (e) Conidium median view. Bars $=50 \mu \mathrm{m}$ (a); $20 \mu \mathrm{m}$ (b, d-e); $10 \mu \mathrm{m}$ (c)
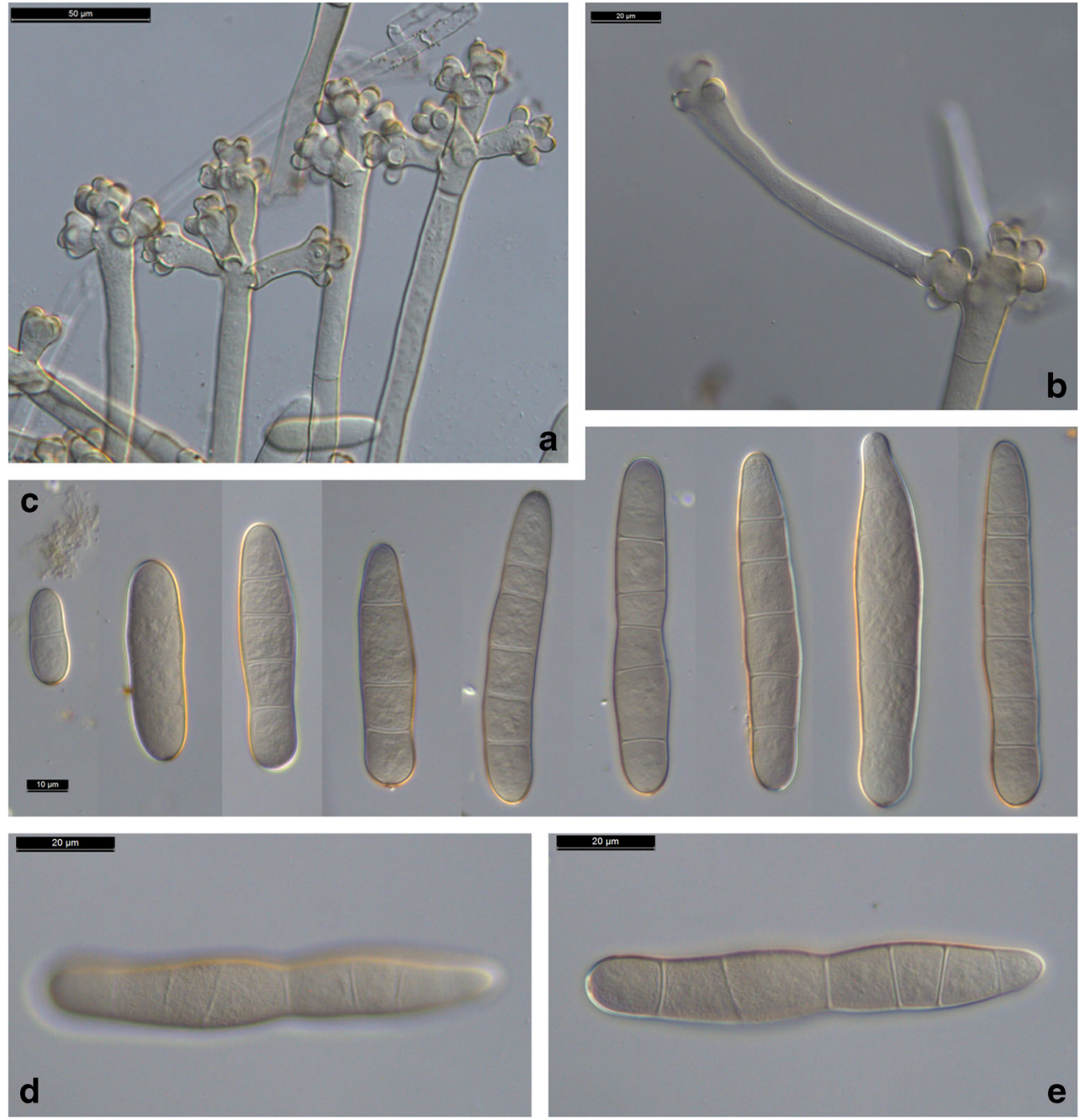

$20 \mu \mathrm{m}$

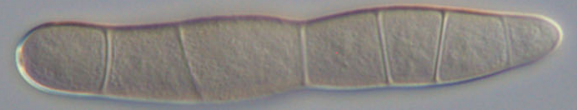

e

Fig. 3 Pathogenicity test results of Dichotomophthora sp. on its original host - Anredera cordifolia (a); Portulaca oleracea (b); Portulaca grandiflora (c); and Zigocactus truncatus - not pathogenic (d). See text for incubation time and conditions
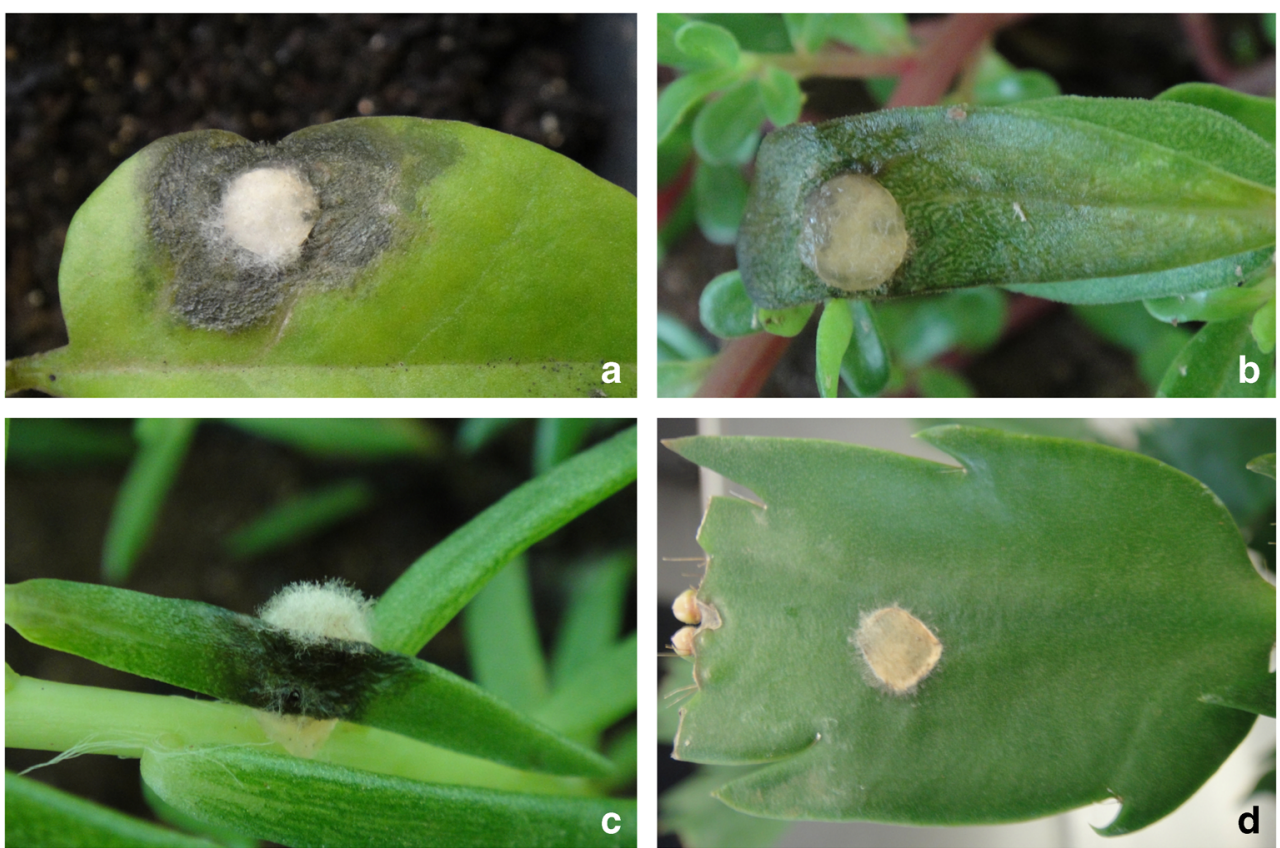
similarities we are convinced that the "Bipolaris sp." reported by Zhang et al. (2011) occurring on B. alba in Florida and the "D. portulacae" reported by Jing et al. (2008) occurring on B. rubra in China, are the same species. Moreover, it seems that the fungus occurring on members of Basellaceae belongs to a distinct species within the genus Dichotomophthora. However, due to the lack of DNA data of the Dichotomophthora species described so far, this hypothesis cannot be corroborated without further studies.

Acknowledgements The authors would like to thank Danilo B. Pinho for his help on molecular analysis.

\section{References}

CABI (2015) Invasive species compendium: datasheet report for Anredera cordifolia (Madeira vine) http://www.cabi.org/isc/ datasheet/112290. Accessed 16 Feb 2017

Da Ponte JJ, Freire FCO (1972) Dichotomophthora cactacearum sp. n. agent of the cactus blue rot. Boletim Cearense de Agronomia $13: 13-16$ de Hoog GS, van Oorschot CAN (1983) Taxonomy of the Dactylaria complex. I. Notes on the genus Dichotomophthora. Proc Kon Ned Akad Wetensch C 86:55-61

Eken C (2003) Dichotomophthora portulacae on Portulaca oleracea in Turkey. Mycotaxon 87:153-156

Farr DF, Rossman AY (2017) Fungal Databases, U.S. National Fungus Collections, ARS, USDA. https://nt.ars-grin.gov/fungaldatabases/. Accessed 16 Feb 2017

Green MR, Sambrook J (2012) Molecular cloning: a laboratory manual, 4th edn. Cold Spring Harbor Laboratory Press, New York

Heywood VH, Brummitt RK, Culham A, Seberg O (2007) Flowering plant families of the world. Firefly Books, Ontario

Jing J, Diao L-G, Lu B-S, Li B-D (2008) The finding of Dichotomophthora portulacae in China. Mycosystema 27:601-603

White TJ, Bruns T, Lee S, Taylor J (1990) Amplification and direct sequencing of fungal ribosomal RNA genes for phylogenetics. In: Innis MA, Gelfand DH, Sninsky JJ, White TJ (eds) PCR protocols: a guide to molecular methods and applications. Academic Press, New York, pp 315-322

Zhang S, Fu S, Mersha Z, Mo X, Palmateer AJ (2011) First report of a leaf spot on caused by a Bipolaris sp. in Florida. Plant Dis 95(7):880 880 